MS JASMIEN OBBELS (Orcid ID : 0000-0001-6351-1543)

PROFESSOR PASCAL SIENAERT (Orcid ID : 0000-0002-0650-415X)

Article type : Original Article

\title{
Neurocognitive functioning after electroconvulsive therapy in late-life depression: a four-year prospective study
}

\section{Obbels Jasmien', Vansteelandt Kristof ${ }^{1}$, Bouckaert Filip², Dols Annemiek³, Stek Max ${ }^{3}$, Verwijk Esmée ${ }^{4}$, Sienaert Pascal ${ }^{1}$ \\ ${ }^{1}$ KU Leuven - University of Leuven, University Psychiatric Center KU Leuven, Academic Center for ECT and Neuromodulation (AcCENT), Leuvensesteenweg 517, 3070 Kortenberg, Belgium}

2 KU Leuven - University of Leuven, University Psychiatric Center KU Leuven, Old-age Psychiatry, Leuvensesteenweg 517, 3070 Kortenberg, Belgium

${ }^{3}$ Department of Old Age Psychiatry, GGZ inGeest/ Amsterdam UMC, location VUmc, Amsterdam Public Health research institute, Amsterdam Neuroscience, Amsterdam, the Netherlands

${ }^{4}$ Department of Medical Psychology, Neuropsychology Department, Amsterdam UMC, Academic Medical Center, Amsterdam, The Netherlands; Department of Psychology, Brain \& Cognition, University of Amsterdam, Amsterdam, The Netherlands; Parnassia Psychiatric Institute, ECT department, The Hague, The Netherlands

Corresponding author: Jasmien Obbels, KU Leuven - University of Leuven, University Psychiatric Center KU Leuven, Academic Center for ECT and Neuromodulation (AcCENT), Leuvensesteenweg 517, 3070 Kortenberg, Belgium.

Tel: +3227580731

Fax: +3227595380

This article has been accepted for publication and undergone full peer review but has not been through the copyediting, typesetting, pagination and proofreading process, which may lead to differences between this version and the Version of Record. Please cite this article as doi: 10.1111/ACPS.13252

This article is protected by copyright. All rights reserved 
E-mail: jasmien.obbels@upckuleuven.be

\section{Abstract}

Objective: Despite the proven efficacy and safety of ECT, there is still concern about the possible cognitive side-effects of ECT in older patients. In this study we aimed to characterize the long-term cognitive effects of ECT in patients with late-life depression (LLD) from before the start until four years after the index ECT course.

Methods: 41 patients aged 55 years and older with a unipolar depression, referred for ECT were included. The neuropsychological test battery was assessed prior to ECT, 6 months, 1 year, 2 years, 3 years and 4 years after the last ECT session.

Results: We did not find any statistically significant cognitive changes from before the start to four years after ending the ECT-course. Although we could not detect cognitive changes at group level, we found clinically important differences on an individual level.

Conclusion: Cognitive performance in patients with LLD run a stable course from before the start of ECT until four years after the index course. At an individual level, however, both cognitive decline and improvement can be witnessed. Older patients can tolerate ECT and most of them will not experience long-term cognitive side-effects.

Key words: ECT, depression, cognition, old age.

\section{Significant outcomes:}

- A course of ECT in patients with late-life depression does not cause significant cognitive changes from before the start of ECT until four years after the index course.

${ }^{\circ}$ Cognitive decline and improvement were present at an individual level, although at a group level no significant cognitive changes were detected. At an individual level, an impact of normal aging cannot be ruled out.

\section{Limitations:}

- Missing of data due to patients drop-out must be taken into consideration when interpreting our results.

-Autobiographical memory was not assessed. 
- The possible impact of practice effects was not assessed.

\section{Conflict of interest:}

The authors have no financial conflicts or other conflict of interest to disclose.

\section{Data availability statement:}

The data that support the findings of this study are available from the corresponding author upon reasonable request.

\section{Introduction}

Depressive disorder is the most common mental disorder in people over 60 , affecting $7 \%$ of the older population (1). Although, in older persons, depression accounts for $5.7 \%$ of years lived with disability (1) and is associated with an increased risk of death (2), it is still undertreated (3). Electroconvulsive therapy (ECT) is a safe, effective, and tolerable antidepressant for patients with late-life depression (LLD) (4), and it is used frequently in old age (5-7). An older age, even in the presence of somatic comorbidity and/or age-related brain changes, predicts a better therapeutic outcome (8-11). However, despite its proven efficacy and safety, there is still concern about the possible cognitive side-effects of ECT in older patients who may be more vulnerable to these effects than younger patients $(12,13)$. The possible negative impact of ECT on cognition is one of the major reasons why patients 
are afraid of ECT (14), why there is a long-standing stigma associated with ECT and why clinicians are reluctant to prescribe it in geriatric patients.

The recent PRIDE-study (15), however, demonstrated only minor acute cognitive sideeffects in 240 LLD-patients, aged 60 or higher. These data confirm the conclusions of 3 earlier reviews: cognitive effects of ECT in LLD are limited and transient (16-18). The studies included in these reviews, however, suffer important methodological limitations. Global cognitive screening instruments are used, in small sample sizes, lacking homogeneity in diagnoses. High attrition rates are reported and results are described on a group level $(18,19)$. It remains unclear which factors are associated with the severity and persistence of cognitive side-effects $(18,19)$. There are, for example, conflicting results on the impact of the number of ECT-sessions, depression severity and age (20-24).

Moreover, there is a lack of long-term follow-up studies. Only 5 studies investigated the impact of ECT on cognition in older patients one-year or longer after ending an ECT-course (25-29). These studies showed that neuropsychological performance did not change $(26,28,29)$ or showed a small improvement $(25,27)$ during the long-term follow-up. None of these studies used a comprehensive neuropsychological test battery. Only global cognitivescreening-instruments, like the Mini Mental State Examination (30) and the Mattis Dementia Rating Scale (31) were used and follow-up was limited to a maximum of two years after ending the ECT treatment. To our knowledge, only Stoudemire et al. (25) investigated cognitive side-effects during a longer follow-up period. In that study, 74 patients (mean age of 72 years $(S D=7)$ ) were followed during four years. Cognitive function, as measured with the Mattis Dementia Rating Scale, either did not change, or improved (25).

Our study is the first to use an extensive neuropsychological test battery in patients with LLD, up to four years after finishing an ECT course, assessing cognitive function before ECT, after six months, 1 year, 2 years, 3 years, and 4 years. We also aimed to investigate whether we could find different individual courses in cognitive performance from baseline until fouryears of follow-up.

\section{Methods}




\subsection{Participants}

This naturalistic four-year longitudinal study was part of the Mood Disorders in Elderly treated with ECT study (MODECT) investigating the clinical and structural brain characteristics and response to ECT (32) and builds further on an earlier study of our group on cognitive effects of ECT after six months (23). Our study was conducted at the University Psychiatric Center (KU Leuven), a tertiary psychiatric hospital in Belgium. Inclusion criteria for patients were an age of 55 years and older, a diagnosis of a unipolar depression according to DSM-IV-TR criteria (33) and a referral for an ECT treatment. Exclusion criteria were a DSM-IV psychiatric illness of bipolar disorder or schizoaffective disorder and a (history of) neurological illness (including stroke, dementia and Parkinson's disease). Fortyone patients met the inclusion/exclusion criteria and provided their written informed consent. The protocol was reviewed and approved by the local ethics review board (Ethical Review Board of the Leuven University Hospitals).

\subsection{ECT procedure}

ECT was administered twice a week with a constant-current brief-pulse (0.5-1 ms) device (Thymatron System IV, Somatics, IL, USA). Etomidate $(0.2 \mathrm{mg} / \mathrm{kg}$ ) and succinylcholine $(1 \mathrm{mg} / \mathrm{kg})$ was used for anaesthetic induction. At the first session, after establishing the subject's seizure threshold (ST), right unilateral ECT (RUL) (d'Elia placement) was administered at 6 times ST. Patients were treated until remission -defined as a MontgomeryÅsberg Depression Rating scale (MADRS) (34) score of less than 10 at two consecutive ratings with a week interval-, or until patients showed no further improvement during the last 2 weeks of ECT. Switching to bitemporal ECT (1.5xST) was applied when, after six RUL treatments, there was insufficient clinical improvement. Psychotropic medication was stopped at least one week prior to ECT, or if deemed impossible, kept stable from six weeks prior to and during the ECT course.

\subsection{Assessments}

\subsubsection{Clinical assessment}

The 30-item Geriatric Depression Scale (GDS) (35) was used to assess the depressive symptom severity one week prior to ECT, six months, one year, two years, three years and 
four years after the last ECT. Diagnosis of depression were defined by the DSM-IV criteria (33) and confirmed by the Mini International Neuropsychiatric Interview (MINI) (36). Demographic variables and medication use were obtained by interview.

\subsubsection{Neuropsychological assessment}

An extensive neuropsychological test battery, assessed by a trained neuropsychologist, was used to determine cognitive functioning. The neuropsychological test covered the domain of attention, executive functioning and memory (see Table 1 for a description of the test battery). The test battery was assessed in the week before the start of the treatment course, 6 months, 1 year, 2 years, 3 years and 4 years after the last acute ECT session.

We compared the neuropsychological test performance at baseline of our sample with test performance from a matched representative normal population without a history of depression. The data of the matched normal population were obtained from studies and test manuals describing normative data $(38,39,43-45)$. We tested whether the z-scores of our sample of patients with a depression were significantly below zero indicating significant cognitive impairment compared to the healthy control group. Results (see supplementary material for further details) indicate that depressed patients in our sample at baseline (before the start of ECT) performed significantly worse compared to the healthy control group on all the neuropsychological tests (with exception of the Meander Luria). For example, using z-scores, our sample scored at baseline on average 0.97 standard deviations below the mean of the healthy normative group on the Fluency Test-Animals 0.97 is significantly below zero; $\mathrm{t}(36)=-7.40, \mathrm{p}<0.0001)$.

\subsection{Statistical analysis}

To examine whether age, global cognitive functioning (MMSE) and depression-severity (GDS) at baseline could predict dropout, a logistic regression model with these predictors and dropout as criterion ( 1 =drop-out, $0=$ still in the study at 4 year follow-up time point) was performed.

To investigate the change of the scores on the cognitive tests over the different discrete time points (baseline, and respectively 6 months, one year, two years, three years and four years 
post-ECT) Linear Mixed Models (LMMs) (46) were estimated for each cognitive variable with repeated measurements (level 1) being nested within patients (level 2). Firstly, we estimated LMMs without covariates. Secondly, we examined the effect of age as timeinvariant predictors in the model. In addition, we examined the effect of depression at the time of assessment, and number of ECT sessions since the previous assessment by including these variables as time-varying predictors in the model. Model selection and selection of the adequate variance-covariance structure was based on likelihood ratio tests and information criteria (46). When the overall F-test for time revealed significant differences between time points, pair-wise post-hoc comparisons between time points were performed using TukeyKraemer adjustments for multiple testing. LMMs can properly account for the correlation between repeated measurements on the same subject, use all available data, and inference is valid under the assumption of Missingness At Random (MAR) $(46,47)$.

\section{Results}

\subsection{Clinical and demographic characteristics}

Figure 1 shows a flow chart of the patient selection. Clinical and demographic characteristics of the patients who were included are shown in Table 2. Patients had a mean age of 73.17 $(\mathrm{sd}=7.43, \min =59, \max =86)$. The sample consisted of 12 men (29\%) and 29 women (71\%). The mean GDS score decreased significantly from 23.19 (SE=0.77, $\min =12.5$, max=29) at baseline to $9.4(\mathrm{SE}=1.77, \mathrm{~min}=0, \max =26.5)$ at the four-year follow-up measurement $(F(1,19.6)=53.62, p<0.0001)$. In 31 (76\%) patients, RUL ECT was used. 10 (24\%) patients were treated with bilateral ECT or switched from unilateral to bilateral ECT during their treatment course. During the follow-up period of 4 years, $15(37,5 \%)$ patients started a second ECT-course, after which 10 (66\%) patients had maintenance ECT. Two patients had a third ECT-course. We refer to the article of Dols and colleagues (32) to obtain a more detailed description of the demographics and clinical characteristics of the Belgian sample. Patients who completed the neuropsychological assessment at four years, did not differ from patients that dropped out in terms of age, baseline GDS-score and baseline MMSE-score $\left(X^{2}(3)=3.44, p=0.33\right)$.

\subsection{Neuropsychological assessment}




\subsubsection{Evolution of cognitive variables from before ECT to four years after ECT without covariates}

Performance on all the neuropsychological tests did not change during the four years of follow-up (Table 3) with the exception of the Meander Figure Test. Raw scores on the Meander Figure Test were, compared to baseline, significant lower at two $(\mathrm{t}(118)=-2.99, \mathrm{p}=$ $0.04)$ and three years $(t(119)=-3.28, p=0.02)$ after finishing the ECT course.

\subsubsection{Evolution of cognitive variables from before to four years after ECT in relation to demographic and clinical variables}

After adjustment for the covariates, we could not find any statistically significant changes from before the start to four years after ending the ECT-course on any of the cognitive variables. We did not find any association between the cognitive evolution over time and the number of ECT sessions since the previous assessment. However, we found a main effect of age on five neuropsychological tests. At every time point, older patients performed worse than younger patients on the VAT A $(F(1,36)=4.96, p=0.03)$, RAVLT total score $(\mathrm{F}(1,41)=8.06, \mathrm{p}=0,007)$, RAVLT 7A $(\mathrm{F}(1,42)=10.59, \mathrm{p}=0.002)$, TMT A $(\mathrm{F}(1,41)=7.39$, $\mathrm{p}=0.001)$ and Category Fluency Test-Animals $(\mathrm{F}(1,49)=4.06, \mathrm{p}=0.049)$. We did not found effects of the GDS-scores except for a negative association between GDS-scores and the performance on the Meander Figure Test two years after ending the ECT-course (time $x$ GDS interaction: $F(5,87.3)=2.57, \mathrm{p}=0.03$; slope for GDS after two years different from zero: $t(87.2)=-3.83, p=0.0002)$, and a negative association between GDS-scores and performance on the RAVLT 7A at all assessment (main effect: $F(1,49)=4.06, p=0.049$ ).

\subsubsection{Individual differences in cognitive performance}

Although we could not detect significant cognitive changes at a group level, we found individual differences among our patients at an individual level using the reliable change index. Table 4 shows that neuropsychological performance in some patients significantly deteriorated, whereas in others, it improved or remained stable. For example, Figure 2 shows individual differences in cognitive scores on the Visual Association Test.

This article is protected by copyright. All rights reserved 


\section{Discussion}

Cognitive performance, assessed with an extensive cognitive battery, in patients with LLD, runs a stable course from before the start of ECT until four years after the index course. These findings corroborate Stoudemire's results (25), failing to detect a significant change in cognitive function during 4 years after an index course of ECT, as measured with a global screening instrument (Mattis Dementia Rating Scale). Likewise, previous studies with a follow-up period of six to 24 months also suggested that older adults can tolerate ECT remarkably well $(18,21)$.

We could not find an association between neuropsychological performance over time and the total number of ECT sessions. This strengthens the idea of other authors (48) that a higher number of ECT-sessions during maintenance ECT does not cause additional deleterious effects on cognitive function.

Our finding that a higher age, at every point in time, predicted a decreased learning capacity and delayed recall and a lower processing speed is consistent with normal aging $(49,50)$. It is, most probably, not related to ECT.

Although we could not detect cognitive changes at a group level, we found that cognitive function in a small number of patients improved or declined during the four-year follow-up period. For example, as shown in Table 4, on the VAT A, one patient (7\%) performed significantly worse, 11 patients (73\%) remained stable and 3 (20\%) patients performed significantly better. Several authors, although investigating individual differences during a shorter follow-up period (until 6 months post-ECT), have reported similar findings $(23,51$ 53). At present, we know little about why some patients' cognitive function will improve and others' will decline after ECT. In our study, the number of patients experiencing a significant change in their cognitive functions was too small to analyze possible predictors.

Hypothetically, it has been argued that individuals differ in the way they cognitively evolve during their aging process (54). Consequently, a wide individual variation in paths of cognitive change is just part of normal aging. Wilson et al. (54) found in a large group of 
healthy non-demented participants of 65 or older that, over a period of six years, cognitive function of some participants declined sharply, some declined gradually, and some stayed unchanged or improved. This is also in line with the study of Schouws et al. (55) who found that older patients with a bipolar disorder did not have greater cognitive decline over a fiveyear follow-up period as compared to a healthy control group. Our group of older patients with a unipolar depression seems to have a similar cognitive course during the four-year follow-up period.

One could argue that an improvement in cognitive performance mirrors an improvement of depression after ECT. We did not, however, find such an association, nor did several others $(15,21,56)$. Nevertheless, interpreting cognitive performance after ECT, the impact of the depressive status cannot be overlooked. During acute phases of LLD, deficits have been observed across a wide range of cognitive domains (57-59). Moreover, longitudinal studies in older patients, as in adults, conclude that cognitive deficits could persist during remission $(60,61)$. Our results confirm these findings. Our patients performed worse on almost every cognitive test at baseline and at four years follow-up, compared to healthy controls. Our findings are in line with the "scar hypothesis" $(62,63)$, stating that recurrent depressive episodes are associated with more cognitive problems during aging.

The patients who showed cognitive decline did so on various neuropsychological tests. No pattern emerged from the data, and the number of 'cognitive decliners' was too small to perform statistical analyses. It is possible that the few patients who showed some form of cognitive decline during follow-up suffered from a (subclinical) neurodegenerative disorder, although patients with a (suspected) neurodegenerative disorder were excluded at baseline. It is also not impossible that some patients developed a neurodegenerative disorder during the follow-up period. An older age is, off course, associated with a higher prevalence of dementia in a normal population (64). Moreover, depression in later life is, likewise, associated with an increased risk of dementia $(65,66)$. ECT, however, as shown in two large population-based studies $(67,68)$ and in our study, is not associated with an increased risk of dementia. These findings support the use of ECT in older patients with affective disorders.

This article is protected by copyright. All rights reserved 
Our study is not without limitations. Firstly, we have missing data due to patients drop-out. At 4 years follow-up, only 18 patients were assessed, limiting the generalizability of our results. Missing of data must be taken into consideration when interpreting our results. Moreover, the small sample size did not allow for the comparison of different clinical and demographic characteristics between the groups of cognitive stable participants, decliners and improvers.

Secondly, we did not include an assessment of autobiographical memory. Although studies that have investigated the impact of ECT on autobiographical memory shortly after ending ECT conclude that autobiographical memory impairment seems to persist longer than other cognitive side-effects (69), studies investigating the long-term impact are lacking.

Thirdly, the lack a control arm with a group of older patients with a unipolar depression not treated with ECT precludes ruling out that the individual differences in cognitive performance are associated with other interventions than ECT during the four-year followup period.

A final limitation is the possible impact of practice effects. It has been shown that a performance on a cognitive test benefits from a previous experience with the test $(54,70)$. Therefore, it is possible that the observed levels of cognitive decline after multiple testing are an underestimation of the actual levels of decline during the four-year follow-up period.

To our knowledge, this is the first study that investigated the long-term cognitive effects up to four years after ECT, using an extensive cognitive test-battery, in a larger group of patients with LLD. It is reassuring to notice that in this age-group, cognitive performance did not change from baseline to four years after ECT. At an individual level, however, both cognitive decline and improvement can be witnessed. These individual differences could be part of normal cognitive aging. Older patients can tolerate ECT and most of them will not experience long-term cognitive side-effects.

This article is protected by copyright. All rights reserved 


\section{References}

1. World Health Organization. Mental health of older adults. https://www.who.int/en/news-room/fact-sheets/detail/mental-health-of-older-adults. Accessed April 15, 2020.

2. Byers AL, Covinsky KE, Barnes DE, Yaffe K. Dysthymia and depression increase risk of dementia and mortality among older veterans. Am J Geriatr Psychiatry 2012;20:664-672.

3. Crystal S, Sambamoorthi U, Walkup JT, Akincigil A. Diagnosis and treatment of depression in the elderly medicare population: predictors, disparities, and trends. J Am Geriatr Soc 2003;51:1718-1728.

4. Kellner CH, Obbels J, Sienaert P. When to consider electroconvulsive therapy (ECT). Acta Psychiatr Scand 2020;141:305-315.

5. Thompson JW, Weiner RD, Myers CP. Use of ECT in the United States in 1975, 1980, and 1986. Am J Psychiatry 1994;151:1657-1661.

6. Nordanskog P, Hultén M, Landén M, Lundberg J, von Knorring L, Nordenskjöld A. Electroconvulsive therapy in Sweden 2013: Data from the national quality register for ECT. J ECT 2015;31:263-267.

7. Lesage A, Lemasson M, Medina K, et al. The prevalence of electroconvulsive therapy use since 1973: a meta-analysis. J ECT 2016;32:236-242.

8. van der Wurff FB, Stek ML, Hoogendijk WJG, Beekman ATF. The efficacy and safety of ECT in depressed older adults: a literature review. Int J Geriatr Psychiatry 2003;18:894-904. 
9. Kellner CH, Greenberg RM, Murrough JW, Bryson EO, Briggs MC, Pasculli RM. ECT in treatment-resistant depression. Am J Psychiatry 2012;169:1238-1244.

10. Bouckaert F, Dols A, Emsell L, et al. Relationship between hippocampal volume, serum BDNF, and depression severity following electroconvulsive therapy in late-life depression. Neuropsychopharmacology 2016;41:2741-2748.

11. van Diermen L, van den Ameele S, Kamperman AM, et al. Prediction of electroconvulsive therapy response and remission in major depression: meta-analysis. $\mathrm{Br} \mathrm{J}$ Psychiatry 2018;212:71-80.

12. Zervas IM, Calev A, Jandorf L, et al. Age-dependent effects of electroconvulsive therapy on memory. J ECT 1993;9:39-42.

13. van der Wurff FB, Stek ML, Hoogendijk WJG, Beekman ATF. Discrepancy between opinion and attitude on the practice of ECT by psychiatrists specializing in old age in the Netherlands. J ECT 2004;20:37-41.

14. Obbels J, Vanbrabant K, Verwijk E, Bouckaert F, Vansteelandt K, Sienaert P. Monitoring ECT-related anxiety: the ECT-related anxiety questionnaire (ERAQ). J ECT 2020;36:180-186..

15. Lisanby SH, McClintock SM, Alexopoulos G, et al. Neurocognitive effects of combined electroconvulsive therapy (ECT) and venlafaxine in geriatric depression: phase 1 of the PRIDE study. Am J Geriatr Psychiatry 2020;28:304-316.

16.Tielkes CEM, Comijs HC, Verwijk E, Stek ML. The effects of ECT on cognitive functioning in the elderly: a review. Int J Geriatr Psychiatry 2008;23:789-795.

17. Gardner BK, O' Connor DW. A review of the cognitive effects of electroconvulsive therapy in older adults. J ECT 2008;24:68-80. 
18. Kumar S, Mulsant BH, Liu AY, Blumberger DM, Daskalakis ZJ, Rajji TK. Systematic review of cognitive effects of electroconvulsive therapy in late-life depression. Am J Geriatr Psychiatry 2016;24:547-565.

19. van Kessel M, Van Der Vlugt J, Spaans H, Murre J, Verwijk E. Pre-treatment predictors of cognitive side effects in depressed patients treated with ECT: a systematic review. Brain Stimul 2019;12:489-489.

20. Semkovska M, McLoughlin DM. Objective cognitive performance associated with electroconvulsive therapy for depression: a systematic review and meta-analysis. Biol Psychiatry 2010;68:568-577.

21. Verwijk E, Comijs HC, Kok RM et al. Short-and long-term neurocognitive functioning after electroconvulsive therapy in depressed elderly: a prospective naturalistic study. Int Psychogeriatr 2014;26:315-324.

22. Bosboom PR, Deijen JB. Age-related cognitive effects of ECT and ECT-induced mood improvement in depressive patients. Depress Anxiety 2006;23:93-101.

23. Obbels J, Verwijk E, Vansteelandt K, et al. Long-term neurocognitive functioning after electroconvulsive therapy in patients with late-life depression. Acta Psychiatr Scand 2018;138:223-231.

24. Obbels J, Vansteelandt K, Verwijk E, et al. MMSE changes during and after ECT in late-life depression: a prospective study. Am J Geriatr Psychiatry 2019;27:934-944.

25. Stoudemire A, Hill CD, Morris R, Martino-Saltzman D, Lewison B. Long-term affective and 
cognitive outcome in depressed older adults. Am J Psychiatry 1993;150:896-900.

26. Stoudemire A, Hill CD, Marquardt M, Dalton S, Lewison BJ. Recovery and relapse in geriatric depression after treatment with antidepressants and ECT in a medical-psychiatric population. Gen Hosp Psychiatry 1998;20:170-174.

27. Huuhka M, Korpisammal L, Haataja R, Leinonen E. One-year outcome of elderly inpatients with major depressive disorder treated with ECT and antidepressants. J ECT 2004;20:179-185.

28. Navarro V, Gastó C, Lomeña F. No brain perfusion impairment at long-term follow-up in elderly patients treated with electroconvulsive therapy for major depression. J ECT 2004;20:89-93.

29. Navarro V, Gastó C, Torres X, et al. Continuation/maintenance treatment with nortriptyline versus combined nortriptyline and ECT in late-life psychotic depression: a twoyear randomized study. Am J Geriatr Psychiatry 2008;16:498-505.

30. Folstein MF, Folstein SE, McHugh PR. "Mini-mental state". A practical method for grading the cognitive state of patients for the clinician. J Psychiatr Res 1975;12:189-198.

31. Mattis S. Dementia Rating Scale: professional manual. Odessa: Psychological Assessment Resources; 1988.

32. Dols A, Bouckaert F, Sienaert P, et al. Early- and late-onset depression in late life: a prospective study on clinical and structural brain characteristics and response to electroconvulsive therapy. Am J Geriatr Psychiatry 2017;25:178-189.

33. American Psychiatric Association. Diagnostic and statistical manual of mental disorders. Washington: American Psychiatric Press; 2000. 
34. Montgomery SA, Åsberg M. A new depression scale designed to be sensitive to change. Br J Psychiatry 1979;134:382-389.

35. Yesavage JA, Brink TL, Rose TL, et al. Development and validation of a geriatric depression screening scale: a preliminary report. J Psychiatr Res 1983;17:37-49.

36. Sheehan DV, Lecrubier Y, Sheehan KH, et al. The Mini-International Neuropsychiatric Interview (M.I.N.I.): the development and validation of a structured diagnostic psychiatric interview for DSM-IV and ICD-10. J Clin Psychiatry 1998;59:22-33.

37. Reitan RM. Trail-Making Test. Arizona: Reitan Neuropsychology Laboratory; 1979.

38. Shulman KI, Gold DP, Cohen CA, Zucchero CA. Clock-Drawing and dementia in the community: a longitudinal study. Int J of Geriatr Psychiatry 1993;8:487-496.

39. Lindeboom J, Jonkers C. Handleiding Amsterdamse Dementie Screening. Amsterdam: Pearson; 1989.

40. Ploeg FAE, van der Luteijn F, Verhage F. Groninger Intelligentie Test (GIT). Lisse: Swets \& Zeitlinger; 1983.

41. Rey A. L'examen Clinique en psychologie. Paris: Presses Universitaires de France; 1964.

42. Lindeboom J, Schmand B, Tulner L, Walstra G, Jonker C. Visual association test to detect early dementia of the Alzheimer type. J Neurol Neurosurg Psychiatry 2002;73:126-133. 
43. Lindeboom J, Schmand B, Christensen. Handleiding: Visuele Associatie Test. Leiden: PITS; 2003.

44. Miatton M, Wolters W, Lannoo E, Vingerhoets G. Updated and extended Flemish normative data of commonly used neuropsychological tests. Psychologica Belgica 2004;44:189-216.

45. Van Toutert MC, Diesfeldt HFA, Hoek, DJ. De Amsterdamse Dementie-Screeningstest (ADS) bij ouderen zonder neurocognitieve stoornis. Implicaties voor de klinische praktijk. Tijdschrift voor Gerontologie en Geriatrie 2016;47:198-210.

46. Verbeke G, Molenberghs G. Linear mixed models for longitudinal data. New york: Springer; 2000.

47. Molenberghs G, Kenward MG. Missing data in clinical studies. Chichester: John Wiley and Sons; 2007.

48. Luccarelli J, McCoy TH, Seiner SJ, Henry ME. Maintenance ECT is associated with sustained improvement in depression symptoms without adverse cognitive effects in a retrospective cohort of 100 patients each receiving 50 or more ECT treatments. J Affect Disord 2020;271:109-114.

49. Davis HP, Small SA, Stern Y, Mayeux R, Feldstein SN, Keller FR. Acquisition, recall, and forgetting of verbal information in long-term memory by young, middle-aged, and elderly individuals. Cortex 2003;39:1063-1091. 
50. Salthouse TA. Selective review of cognitive aging. J Int Neuropsychol Soc 2010;16:754760.

51. Hausner L, Damian M, Sartorius A, Frölich L. Efficacy and cognitive side effects of electroconvulsive therapy (ECT) in depressed elderly inpatients with coexisting mild cognitive impairment or dementia. J Clin Psychiatry 2011;72:91-97.

52. Dybedal GS, Tanum L, Sundet K, Gaarden TL, BjØlseth TM. Cognitive side-effects of electroconvulsive therapy in elderly depressed patients. Clin Neuropsychol 2014;28:10711090.

53. Ziegelmayer C, Hajak G, Bauer A, Held M, Rupprecht R, Trapp W. Cognitive performance under electroconvulsive therapy (ECT) in ECT-naive treatment-resistant patients with major depressive disorder. J ECT 2017;33:104-110.

54. Wilson RS, Beckett LA, Barnes LL, et al. Individual differences in rates of change in cognitive abilities of older persons. Psychol Aging 2002;17:179-193.

55. Schouws SN, Comijs HC, Dols A, Beekman AT, Stek ML. Five-year follow-up of cognitive impairment in older adults with bipolar disorder. Bipolar Disord 2016;18:148-154.

56. McClintock SM, Cullum CM, Husain MM, et al. Evaluation of the effects of severe depression on global cognitive function and memory. CNS Spectr 2010;15:304-313.

57. Hermann LL, Goodwin GM, Ebmeier KP. The cognitive neuropsychology of depression in the elderly. Psychol Med 2007;37:1693-1702. 
58. Köhler S, Thomas AJ, Barnett NA, O'Brien JT. The pattern and course of cognitive impairment in late-life depression. Psychol Med 2010;40:591-602.

59. Pantzar A, Atti AR, Fratiglioni, Fastbom J, Bäckman L, Laukka EJ. 2017. Cognitive performance in unipolar old-age depression: a longitudinal study. Int J Geriatr Psychiatry 2017:32:675-684.

60. Portella MJ, Marcos T, Rami L, Navarro V, Gastó C, Salamero M. Residual cognitive impairment in late-life depression after a 12-month period follow-up. Int J Geriatr Psychiatry 2003;18:571-576.

61. Bhalla RK, Butters MA, Mulsant BH, et al. Persistence of neuropsychological deficits in the remitted state of late-life depression. Am J Geriatr Psychiatry 2006;14:419-427.

62. Lewinsohn PM, Steinmetz JL, Larson DW, Franklin J. Depression-related cognitions: antecedent or consequence? J Abnorm Psychol 1981;90:213-219.

63. Robinson OJ, Sahakian BJ. Recurrence in major depressive disorder: a neurocognitive perspective. Psychol Med 2008;38:315-318.

64. Kukull WA, Higdon R, Bowen JD et al. Dementia and Alzheimer disease incidence: a prospective cohort study. Arch Neurol 2002;59:1737-1746. 
65. Kessing LV. Depression and the risk for dementia. Curr Opin Psychiatry 2012; 25:457461.

66. da Silva J, Goncalves-Pereira M, Xavier M, Mukaetova-Ladinska EB. 2013. Affective disorders and the risk of developing dementia: systemic review. Br J Psychiatry 2013; 202:177-186.

67. Chu CW, Chien WC, Chung $\mathrm{CH}$, et al. Electroconvulsive therapy and risk of dementia: a nationwide cohort study in Taiwan. Front Psychiatry 2018;9:397.

68. Osler M, Rozing MP, Christensen GT, Andersen PK, Jørgensen MB. Electroconvulsive therapy and risk of dementia in patients with affective disorders: a cohort study. Lancet Psychiatry 2018;5:348-356.

69. Fraser LM, O'Carroll RE, Ebmeier KP. The effect of electroconvulsive therapy on autobiographical memory: a systematic review. J ECT 2008;24:10-17.

70. Unger JM, van Belle G, Heyman. Cross-sectional versus longitudinal estimates of cognitive change in nondemented older people: a CERAD study. J Am Geriatr Soc 1999;47:559 -563. 
Table 1. Overview of the neuropsychological test battery

\begin{tabular}{ll}
\hline Test & Domain \\
\hline Trail Making Test A and B & $\begin{array}{l}\text { Processing speed and } \\
\text { divided attention }\end{array}$ \\
(TMT A \& B) (37) & Executive functioning \\
Clock drawing & \\
(subtask “10 past 11") (38) & Executive functioning \\
Meander Figure Test (39) & \\
Letter Fluency Test & Fonemic fluency \\
-"D” (40) & \\
Rey Auditory Verbal & Verbal memory \\
Learning Test (RAVLT) (41) & \\
Visual Association Test & \\
(VAT A) (42) & Visual memory \\
&
\end{tabular}

This article is protected by copyright. All rights reserved 
This article is protected by copyright. All rights reserved 
Table 2. Demographic and clinical characteristics $(N=41)$

Mean age, yr (SD, min-max) $73.17(7.43,59-86)$

Gender, male, n (\%)

$12(29.27)$

GDS, mean (SD, min-max)

Baseline

$23.20(4.42,12.50-29)$

Six months post-ECT

$14.17(8.89,1-29.5)$

1 year post-ECT

$9.61(6.27,1-20.50)$

This article is protected by copyright. All rights reserved 


\begin{tabular}{ll}
\hline 2 years post-ECT & $14.78(8.39,2-27)$ \\
3 years post-ECT & $8.76(6.97,1-24)$ \\
4 years post-ECT & $9.12(7.17,0-26.5)$ \\
Total number of ECT treatments, mean (SD, min-max) & \\
Six months post-ECT & $15.35(9.06,4-40)$ \\
1 year post-ECT & $18.86(14.12,4-54)$ \\
2 years post-ECT & $23.30(20.33,4-85)$ \\
3 years post-ECT & $25.65(23.86,4-86)$ \\
4 years post-ECT & $28.35(27.44,4-107)$ \\
Electrode position, $n(\%)$ & \\
Unilateral & $31(75.61)$ \\
Bilateral or switch from unilateral to bilateral & $10(24.39)$ \\
& \\
Number of previous depressive episodes, mean (IQR) & $3.85(2)$ \\
Late onset $\geq 55$ years) & $23(56.1)$ \\
\hline
\end{tabular}

This article is protected by copyright. All rights reserved 
Notes: SD: standard deviation; GDS: Geriatric Depression Scale.

This article is protected by copyright. All rights reserved 
Table 3. Neuropsychological performances from baseline until four-years after ending ECT

\begin{tabular}{|c|c|c|c|c|c|c|c|c|}
\hline & Baseline & $\begin{array}{l}6 \text { months } \\
\text { post-ECT }\end{array}$ & $\begin{array}{l}1 \text { year post- } \\
\text { ECT }\end{array}$ & $\begin{array}{l}2 \text { years post- } \\
\text { ECT }\end{array}$ & $\begin{array}{l}3 \text { years post- } \\
\text { ECT }\end{array}$ & $\begin{array}{l}4 \text { years } \\
\text { post-ECT }\end{array}$ & F-test & $\begin{array}{l}\text { p- } \\
\text { value }\end{array}$ \\
\hline TMT A & $4.46(0.08)^{a}$ & $4.37(0.08)^{a}$ & $4.28(0.09)^{a}$ & $4.38(0.09)^{a}$ & $4.25(0.09)^{a}$ & $4.30(0.10)^{a}$ & $F(5,104)=1.87$ & 0.11 \\
\hline TMT B & $5.38(0.10)^{a}$ & $5.38(0.11)^{a}$ & $5.18(0.10)^{a}$ & $5.29(0.12)^{a}$ & $5.11(0.14)^{a}$ & $5.14(0.16)^{a}$ & $F(5,48.4)=1.53$ & 0.20 \\
\hline Clock & $2.66(0.23)^{a}$ & $2.55(0.31)^{a}$ & $2.30(0.20)^{a}$ & $2.26(0.26)^{a}$ & $2.45(0.21)^{a}$ & $2.42(0.32)^{a}$ & $F(5,59.8)=0.55$ & 0.74 \\
\hline
\end{tabular}

This article is protected by copyright. All rights reserved 
Drawing

Meander

$3.42(0.22)^{a}$

$3.32(0.24)$ a,b

$2.96(0.26)^{a, b}$

$2.61(0.27)^{b}$

$2.43(0.30)^{b}$

$2.72(0.30)^{a, b} \quad F(5,113)=3.61$

0.004

Figure

Letter
Fluency- "D"

$$
6.59(0.61)^{\mathrm{a}} \quad 7.38(0.65)^{\mathrm{a}} \quad 8.33(0.70)^{\mathrm{a}}
$$

$7.17(0.74)^{\mathrm{a}}$

$8.65(0.82)^{a}$

$7.57(0.84)$ a $\quad F(5,116)=1.64$

0.15

\section{RAVLT}

$25.96(2.14)^{\text {a }} \quad 28.55(1.77)$

$27.82(1.87)^{a}$

$26.91(1.73)^{\text {a }}$

$24.89(1.71)$ a

$25.27(1.81)$ a $\quad F(5,18.6)=1.29$

Delayed

$4.50(0.69)^{\text {a }} \quad 4.63(0.55)^{\text {a }}$

$4.81(0.49)^{\text {a }}$

$4.52(0.59)$ a

$4.06(0.55)^{a}$

$4.52(0.62)$ a $\quad F(5,66.5)=0.36 \quad 0.88$

recall

VAT A

$9.20(0.58)^{\mathrm{a}}$

$10.23(0.42)^{\mathrm{a}}$

$10.32(0.43)^{\mathrm{a}}$

$10.03(0.57)^{\mathrm{a}}$

$10.85(0.33)^{\text {a }}$

$10.21(056)^{\text {a }} \quad F(5,61.5)=1.77$

0.13

Category

$12.84(0.73)^{\text {a }} \quad 13.80(0.78)^{\text {a }}$

$14.67(0.83)^{\text {a }}$

$13.44(0.87)^{a}$

$14.72(0.93)^{\mathrm{a}}$

$14.31(0.99)^{\text {a }} \quad F(5,119)=1.37$

0.24

Fluency

Test-

Animals

This article is protected by copyright. All rights reserved 
Notes: TMT: Trail Making Test; RAVLT: Rey Auditory Verbal Learning Test; VAT: Visual Association Test; SE: Standard Error; Means that do not share the same superscript are significantly different using Tukey-Kramer adjustment for multiple comparisons.

Table 4. Frequency of subjects who decrease, remain stable or increase from baseline to four-years post-ECT on cognitive tasks according to the Reliable Change Index.

\begin{tabular}{ccc}
\hline Decrease & Stable & Increase \\
Frequency (Percent) & Frequency (Percent) & Frequency (Percent)
\end{tabular}

This article is protected by copyright. All rights reserved 


\begin{tabular}{lccc}
\hline TMT A & 0 & $13(92.68)$ & $1(7.14)$ \\
Clock Drawing & $2(13.33)$ & $13(86.67)$ & 0 \\
Meander Figure & $5(33.33$ & $9(60)$ & $1(6.67)$ \\
RAVLT (total & 0 & $13(81.25)$ & $3(18.75)$ \\
score) & $1(6.67)$ & $11(73.33)$ & $3(20)$ \\
VAT A & $1(7.14)$ & $12(85.71)$ & $1(7.14)$ \\
Category Fluency & & & \\
Test-Animals & & & \\
\hline
\end{tabular}

Note: TMT B is not included in the table due to the very small sample of subjects with a TMT B (frequency: 2) score at four-year follow-up.

This article is protected by copyright. All rights reserved 
Figure 1. Flow chart of patient selection

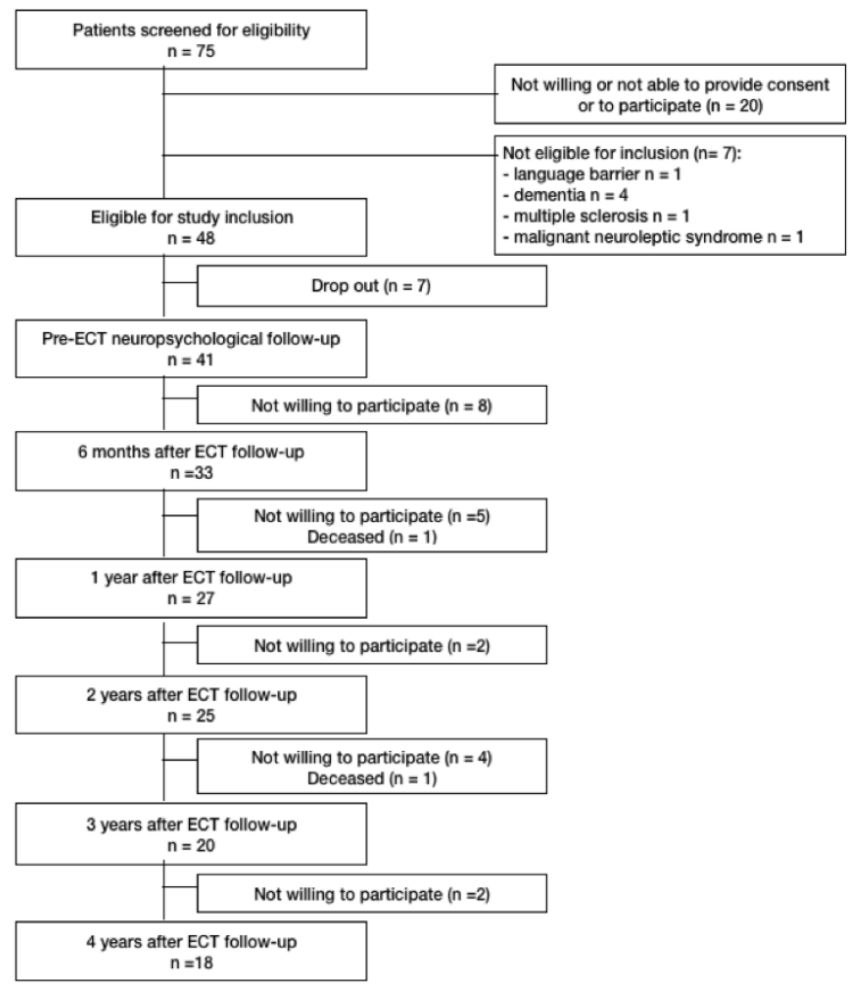

acps_13252_f1.png

This article is protected by copyright. All rights reserved 
Figure 2. Individual differences in cognitive performances on the Visual Association Test (VAT) (from baseline until four-years after ECT).

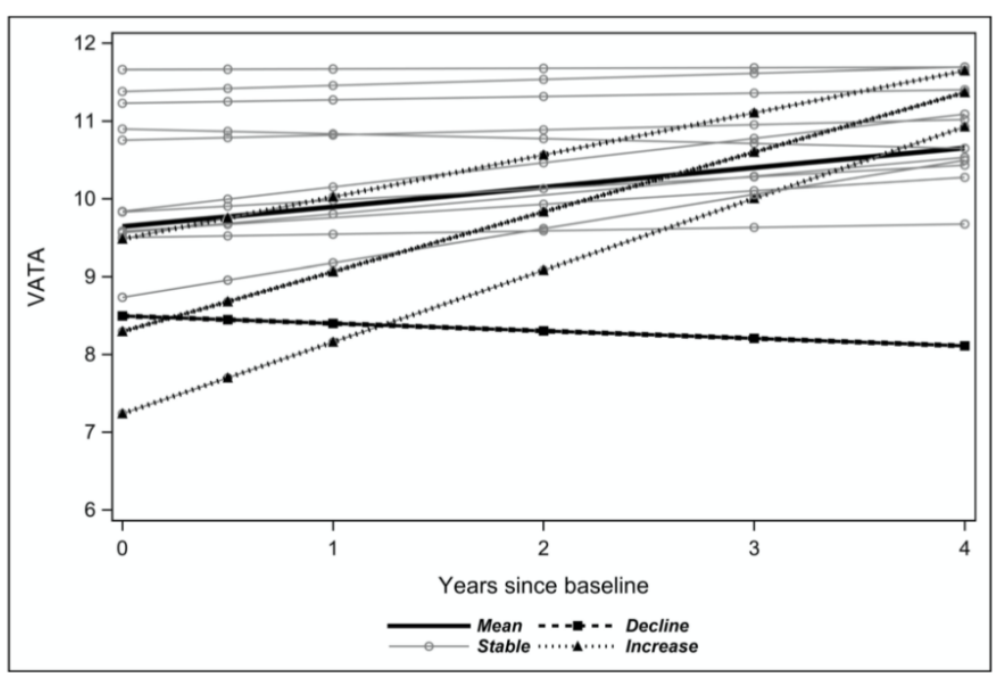

acps_13252_f2.png

This article is protected by copyright. All rights reserved 